RECENSIONES BIBLIOGRÁFICAS

\title{
Abramides Brasil y Natália Marques, Relações de trabalho em plataformas digitais: Desafios ao modelo tradicional do Direito do trabalho. Rio de Janeiro: Lumen Juris, 2019
}

\author{
Rodrigo Monteiro Pessoa \\ Universidad de la Frontera, Chile
}

El mundo del trabajo está cambiando de forma abrumadora. Cada día más, la economía encuentra maneras de reproducir el capital, y utiliza para esto de todo el arsenal que la tecnología le proporciona. En una economía de mercado la dinámica apunta a que sus principales actores busquen, de la mejor forma posible, tomar decisiones racionales a la hora de producir y consumir bienes y servicios (Mankiw, 2012: 4 y ss.). Además, los actores económicos, propietarios de los factores de producción, pretenden multiplicar sus riquezas o sus ingresos, y así poder generar mayor consumo de bienes y servicios, o hacer más inversiones, para seguir multiplicando sus riquezas o ingresos. El crecimiento económico está relacionado con el crecimiento de los factores de producción, y también con los avances tecnológicos (Dornbusch, Fischer e Startz, 2009: 53 y ss.). Estos factores de producción - que incluyen los recursos naturales (tierra), el capital y el trabajo, y sus respectivos rendimientos (renta en el caso de los recursos naturales, interés en el caso del capital y salario en el caso del trabajo; Mochón, 2006: 113) - se emplean para alcanzar sus objetivos de expansión o incremento. Ninguno de los actores económicos actúa en una economía de mercado sin esperar los mejores resultados para consumir bienes o servicios dentro de esta misma economía de mercado.

¿En qué se relaciona esto con los cambios en el mundo del trabajo que apuntamos en el inicio? En que el trabajo es un factor de producción en la economía, y el mercado de trabajo, y su demanda y oferta, representan una parte importante de las políticas macroeconómicas (Dornbusch, Fischer e Startz, 2009: 118 y ss.). Por esta razón, el capital buscará, siempre, la mejor forma de minimizar sus costos y poder multiplicarse de forma más rápida y con menos barreras, y esto incluye la explotación del trabajo, vivo o muerto (Antunes, 2004). Por esto mismo, la Cuarta Revolución 
Industrial (Schwab, 2016) vino a ofertar los avances tecnológicos como mecanismos para la reproducción del capital y para la modificación, aun mayor, de las relaciones de trabajo. Esto significa que, económicamente, el capital encontró un gran aliado, ya que la nueva forma de alcanzar sus objetivos de expansión, por medio de la tecnología, posibilita una rápida conquista reproductiva para los dueños del capital, pero que, por otro lado, genera altos costos para los trabajadores, que están cada día más perdidos en las dinámicas del mercado, viendo, día a día, una abstracción aun mayor de los modelos de empleo que ellos esperaban alcanzar.

Natália Marques Abramides Brasil, magíster en Derecho por la Faculdade de Direito de Ribeirão Preto de la Universidade de São Paulo, hace una vanguardista reflexión sobre estos impactos en el derecho del trabajo, enfocando su investigación en las plataformas digitales, que traen para nuestro quehacer jurídico todas las dudas sobre el tipo de relación laboral que deriva de estas nuevas formas de trabajo. Para comenzar, la autora hace una importante reflexión sobre cómo el concepto de subordinación (capítulo 1), que no es el único criterio diferenciador del contrato de trabajo con los contratos civiles o comerciales (Abramides Brasil, 2019: 16-19), ha evolucionado a lo largo del tiempo. Desde las ideas de Lodovico Barassi en su obra obra Il contrato di lavoro nel diritto positivo italiano, hasta la subordinación objetiva y estructural plateada por el autor brasileño Maurício Godinho Delgado. Es decir, la autora apunta una tendencia expansionista del concepto de subordinación que sirve de base para poder encontrar una solución para los casos del trabajo por las plataformas digitales (Abramides Brasil, 2019: 20).

En el capítulo 2, Natália Marques comenta sobre los mercados de plataforma digital, estableciendo que existe una importante diferencia entre los diversos segmentos de mercado que utilizan las plataformas digitales, lo que impediría generalizar todas las plataformas como posibles generadoras de relaciones de trabajo subordinado. Esta posición es muy acertada, teniendo en cuenta toda la diferencia existente en las plataformas del marketplace, share economy y crowdsourcing o crowdwork (Todolí Signes, 2017). Sería imprudente que la legislación laboral considerase que todas las plataformas digitales actúan de la misma forma, con los mismos actores y con las mismas finalidades. Actualmente, considerando que el derecho del trabajo sigue protegiendo las relaciones subordinadas —únicamente-, solamente las plataformas con énfasis en la prestación de servicios (y no en los bienes) serán objeto de posible reconocimiento de subordinación, y, consecuentemente, de incidencia de las normas laborales. Y esto se resume al crowdwork, en ciertas situaciones.

La maestría del trabajo no termina por aquí. El capítulo 3 es de fundamental importancia para comprender los criterios utilizados por la jurisprudencia brasileña en los fallos judiciales, de procedencia o improcedencia, referentes a las demandas por el reconocimiento de una relación de trabajo como choferes de Uber. La autora separó los principales criterios utilizados en las argumentaciones favorables y contrarias al 
reconocimiento de una relación de trabajo subordinado en los casos específicos de Uber (que se cuadra en el concepto de crowdwork, por ende, posibilita - en algunos casos- la incidencia de las normas laborales). Además de elaborar tablas ilustrativas con los criterios argumentativos y su presencia en el universo de los datos estudiados, hizo importantes resúmenes sobre la forma como los tribunales están comprendiendo el fenómeno de las plataformas digitales en aquel país. Finalizando el capítulo, la autora presenta - como metodología comparativa - la presencia de algunos de estos criterios argumentativos en la jurisprudencia europea y de los Estados Unidos (Abramides Brasil, 2019: 77-146).

En su último capítulo, la obra sistematiza la argumentación construida para demostrar por qué los criterios utilizados por los fallos judiciales brasileños no deberían llevar a comprender el trabajo de los choferes Uber como un trabajo autónomo. Más allá, y con agudeza crítica, analiza cuáles son los criterios favorables de la jurisprudencia de Brasil que reconocen la relación de trabajo de los choferes Uber como subordinada, que necesitaría una relectura por parte de la doctrina laboralista (Abramides Brasil, 2019: 147-77).

Existen muchos desafíos e incertidumbres en el mundo del derecho del trabajo, resultado de las rápidas modificaciones de las relaciones de trabajo en todo el mundo. Por un lado, el trabajo del siglo XXI lucha para mantenerse alejado de los contratos civiles y comerciales, so pena de reducir el trabajo humano a una mercadería (Supiot, 2016: 335), como era visto en tiempos remotos (Monteiro Pessoa, 2019: 23 y ss.). El reconocimiento jurídico de la identidad y de la dignidad del trabajador es fundamental para restituir al trabajo su dimensión antropológica (Supiot, 2016: 340). En este sentido, el libro de Natália Marques arroja luz en las tinieblas, para repensar el derecho del trabajo frente a los cambios tecnológicos y preservar los derechos sociofundamentales de todos aquellos que buscan destinar su fuerza de trabajo para la sociedad.

\section{Referencias}

Abramides Brasil, Natália Marques (2019). Relações de trabalho em plataformas digitais: desafios ao modelo tradicional do Direito do trabalho. Rio de Janeiro: Lumen Juris.

Antunes, Ricardo (2004). A Dialética do Trabalho. São Paulo: Expressão Popular.

Dornbusch, Rudiger, Stanley Fischer e Richard Startz (2009). Macroeconomía. Décima Edi. México: McGrawHill.

Mankiw, N. Gregory (2012). Principios de economía. 6. ${ }^{\text {a }}$ ed. México: CENGAGE Learning.

Mochón, Francisco (2006). Principios de economía. 3. ${ }^{a}$ ed. Madrid: McGrawHill.

Monteiro Pessoa, Rodrigo (2019). Derecho del Trabajo Sistematizado. Temuco: UFRO University Press. 
Schwab, Klaus (2016). La cuarta revolución industrial. Madrid: Debate.

SupIot, Alain (2016). Crítica do Direito do Trabalho. Lisboa: Fundação Calouste Gulbenkian.

Todolí Signes, Adrián (2017). El trabajo en la era de la economía colaborativa. Valencia: Tirant Lo Blanch.

\section{Sobre el autor}

Rodrigo Monteiro Pessoa es profesor de Derecho del Trabajo, Derecho de la Seguridad Social y Economía en la Universidad de la Frontera (Chile). Licenciado en Administración por la Universidade Federal da Paraíba, Brasil; Licenciado en Ciencias Jurídicas por el Instituto Superior de Educação da Paraíba. Brasil; Especialista en Derecho de la Seguridad Social por la UNIDERP, Brasil; Magíster Académico en Derecho Económico por la Universidade Federal da Paraíba, Brasil; Doctor en Derecho por la Universidad de Chile. Miembro de la Sociedad Chilena de Derecho del Trabajo y de la Seguridad Social. Su correo electrónico es rodrigo.pessoa@ufrontera.cl. 